\title{
Assessment, Mapping and Prediction of the Spatial Distribution of Intestinal Parasitic Infections in Rivers State, Nigeria \\ Abah $\mathrm{AE}^{*}$, Arene FOI and Okiwelu SN
}

Department of Animal and Environmental Biology, Faculty of Biological Science, College of Natural and Applied Sciences, University of Port Harcourt, Rivers State, Nigeria

\begin{abstract}
This study assessed the prevalence of intestinal parasitic infections among school-aged children in Rivers state, Nigeria using Geographical Information System (GIS). A total of 3,828 stool samples were collected from school children from thirty six primary schools in thirteen local government areas of the state. The samples were analyzed using wet saline/iodine and formal ether concentration methods. The parasites found were identified. The location of the schools was linked to prevalence data and environmental data using unique schools identifier. Separate layers were created for school location, infection data and environmental data and which were used for map production. Infection prevalence for school was classified into five groups using WHO prevalence classification system, viz: (1) No infection, (2) Light infection $0.1-9.99 \%$, (3) Moderate infection $10-24.9 \%$ (4) Heavy infection $25-49.9 \%$ and (5) Very heavy infection $50 \%$ and above for display in GIS. The spatial analysis was performed using Arc view. The estimated population of school-aged children at risk was calculated by over laying the predictive maps of infection prevalence on a population density map and total extracted. Parasites identified in the study were Ascaris lumbricoides (51.78\%), hookworm $(25.0 \%)$, Trichuris trichiura $(15.18 \%)$, Strongyloides stercoralis $(7.14 \%)$, Taenia $s p .(0.89 \%)$, Enterobis vermicularis $(0.01 \%)$. Current study estimated number of school-aged children (5-14years) at risk of intestinal parasitic infections in Rivers State to be 655,061 (0.65million). This estimate represented the school-aged populations living in areas where the environmental factors, when combined with host/parasite are suitable for the intestinal parasitic infections. The rate of infection showed that Emohua and Ahoada East and their environment need intervention. This study provided for the first time, the rate of infection, risk and prediction maps of prevalence of intestinal parasitic infections in Rivers State. It is hope that the map produced would help policy makers in the deployment of scarce available resources in the management of these diseases.
\end{abstract}

Keywords: GIS; Risk maps; Intestinal parasitic infections; School children; Rivers state

\section{Introduction}

Intestinal parasitic infections have been reported to have high prevalence among children in Nigeria because of their vulnerability [16]. These parasites constitute a global health burden. Yet, information on their mapping is scare. Information on Geo-mapping of Intestinal parasites in Nigeria is scanty and such data are not readily available in Rivers State. In Africa, a 1987 survey was undertaken in Cameroun, $[7,8]$ and a 2002 survey in Uganda [9]. There have been two geostatistical analyses of intestinal nematodes [10,11]. In control and intervention, mapping helps to guide available resources to be most rationally and cost effectively deployed. Geographical Information System (GIS) has greatly contributed to solving many real-world challenges, from agriculture to emergency planning and control. It has been used in the health sector for infectious diseases and other parasitic diseases in Africa and world over [12]. For example, the African Programme for Onchocerciasis Control (APOC) has effectively used GIS to visualize priority areas for mass distribution of Invermetin and estimated the number of people to be treated [12]. However, in Rivers state, Nigeria, there is a dearth of information on the mapping of these parasites. The present study was an attempt to bridge this gap and to help policy makers in the deployment of scarce available resources in the management of these diseases.

\section{Methods}

A total of 36 Primary schools were randomly selected from 13 Local Government Areas, Rivers State; stool samples were collected from 3,828 pupils in the study area. The collected stool samples were analyzed in duplicate, using the concentration and the saline/iodine method according to the standard method of stool examination $[13,14]$. The geographical information system was designed to map the incidence and the prevalence patterns of intestinal parasites in relation to some environmental parameters (temperature, rainfall and relative humidity) following a modified method of Rosa [15] and Ekpo et al., [16]. The geographical co-ordinates (latitude and longitude) of the Schools were recorded using the field Model GPS (Garmin GPS MAP76s Chart plotting receiver). These Geographical data were displayed and analyzed in the ArcGIS (version 10.0 with geostatistical analyst tool, ESRI CA USA). The location of the schools was linked to prevalence data and environmental data using unique schools identifier, separate layers were created for school location, infection data and environmental data for production of the map. Infection prevalence for school was classified into five groups using WHO prevalence classification system [17], these are (1) No infection (2) Light infection $0.1-9.99 \%$ (3) Moderate infection $10-24.9 \%$ (4) Heavy infection $25-49.9 \%$ (5) Very heavy infection $50+\%$ for display in GIS. ArcGIS was used to perform the analysis. Logistic regression models were developed to identify significant environmental variables affecting the transmission of infection using a stepwise elimination technique in SPSS version 10.0 (SPSS Inc, USA).

*Corresponding author: Dr. Austin Abah, Department of Animal and Environmental Biology, Faculty of Biological Science, College of Natural and Applied Sciences, University of Port Harcourt, Rivers State, Nigeria, Tel: 234 8033402311; E-mail: austin.abah@uniport.edu.ng

Received August 31, 2015; Accepted September 01, 2015; Published September 16, 2015

Citation: Abah AE, Arene FOI, Okiwelu SN (2015) Assessment, Mapping and Prediction of the Spatial Distribution of Intestinal Parasitic Infections in Rivers State, Nigeria. J Trop Dis 3: 177. doi:10.4177/2329891X.1000177

Copyright: ( 2015 Abah AE, et al.This is an open-access article distributed under the terms of the Creative Commons Attribution License, which permits unrestricted use, distribution, and reproduction in any medium, provided the original author and source are credited. 
Citation: Abah AE, Arene FOI, Okiwelu SN (2015) Assessment, Mapping and Prediction of the Spatial Distribution of Intestinal Parasitic Infections in Rivers State, Nigeria. J Trop Dis 3: 177. doi:10.4177/2329891X.1000177

\section{Results}

Of the 3,828 children examined for intestinal parasitic infections, $1059(27.66 \%)$ were infected. Parasites identified in the study were Ascaris lumbricoides $51.78 \%$, hookworm 25\%, Trichuris trichiura $15.18 \%$, Strongyloides stercoralis $7.14 \%$, taenia sp $0.89 \%$, Enterobis vermicularis $0.01 \%$. The Co-ordinates (latitude and longitude) obtained using the field Model GPS (Garmin GPS MAP76s Chart plotting receiver) were converted from degrees/minutes/seconds to decimal degrees giving the values for easting and northing. The values were displayed in Arc map/ Arc info version 10.0 and this gave the location of the schools (sampling sites, Figure 1) rate of infections. The geostatistical analyst wizard was employed using the Kriging method. Two data sets were used; number of positive/number examined $\mathrm{x} 100$. This was the determining factor. The value was then imputed into the geostatistical wizard and the map produced (Figure 2). From Figure 2, Ahoada East and Emohua local Government Areas have the highest rate of infection with 50\% and above (very heavy infections). This was closely followed by The Local Government Areas with infection rate ranging from 25-49.9\% (heavy infections), and these areas include; Abua/Odual, Ahoada West, Eleme, Ikwerre, Obio Akpor, Ogba/Egbema/Ndoni, Ogubolo, Okrika, Port Harcourt and Tai Local Government Areas. All the other Local Government areas are within the infection rates of 10-24.9\% (moderate infections) except Asari Toru which has the least infection rate of 0.19.99\% (light infection). Figure 3 shows that more children are at greater risk of infection around Ahoada East and Emuoha than the other areas and are at lower risk of infection around Asari Toru Local Government Area. Predicting the number of school-aged children (5-14 years) at risk of intestinal parasitic infections in Rivers State is 655,061 (0.65 million) Figure 4. Infection is higher around Ahoada east and Emuoha while it is lower around Asari Toru Local Government Areas of the Sta te.

Conversion of the rate of infections from the percentage value using the geostatistical analysis wizard produced the map of probability of

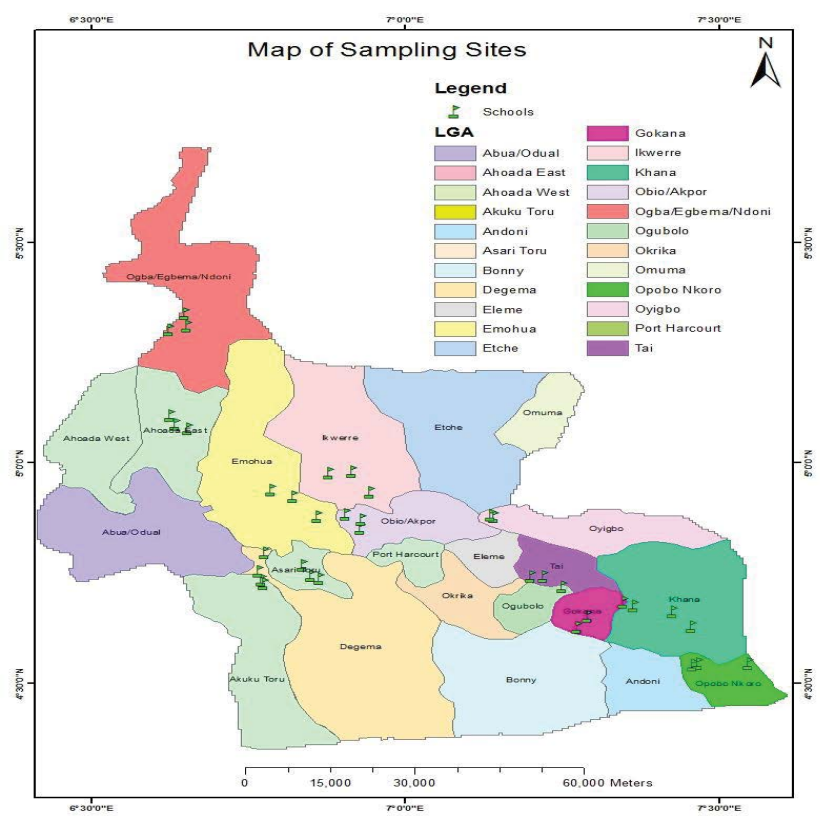

Figure 1: Locations of schools sampled in the study of intestinal parasitic infections among primary school children in Rivers State, Nigeria.

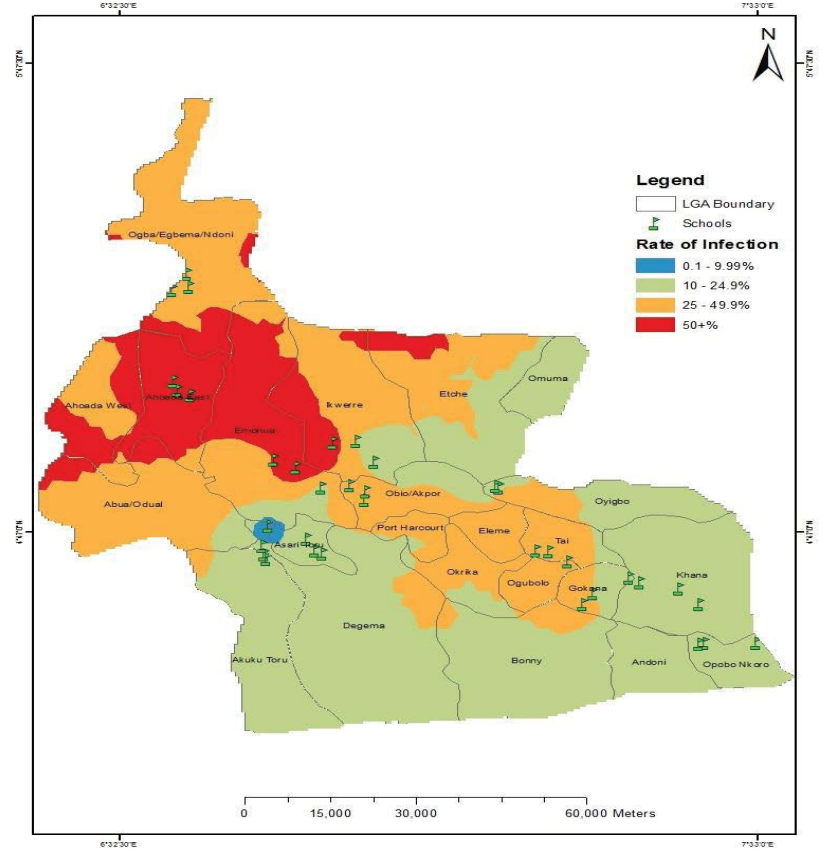

Figure 2: Infection of sampled population in the study of intestinal parasitic infections among primary school children in Rivers state Nigeria.

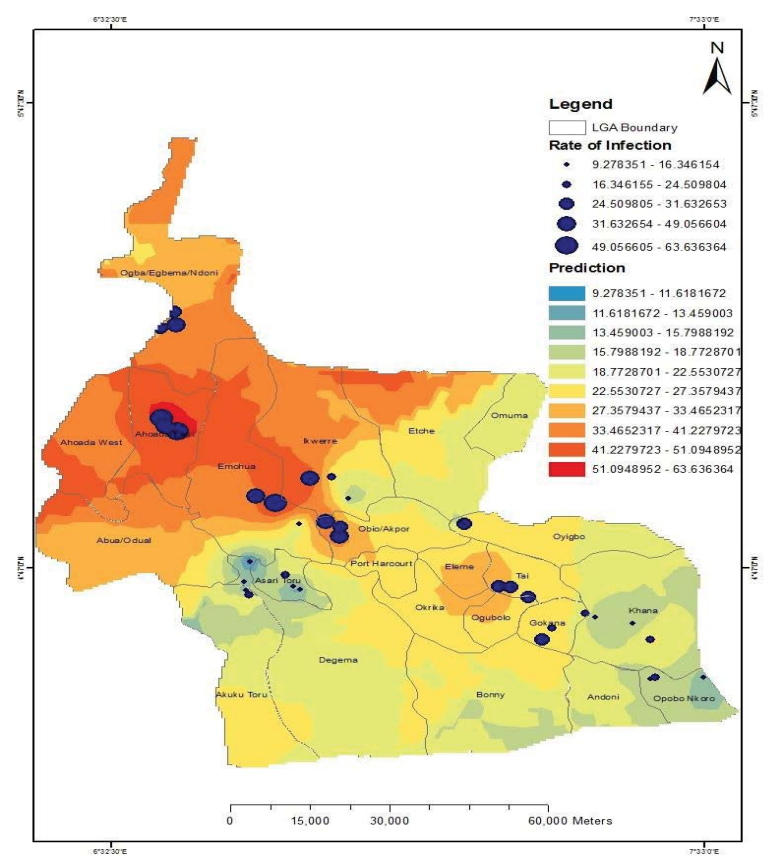

Figure 3: Probability of infection of sampled population in the study of intestinal parasitic infections among primary school children in Rivers State Nigeria.

infection otherwise known as prediction map (Figure 3). More children are at greater risk of infection around Ahoada East and Emuoha than the other areas and are at lower risk of infection around Asari Toru Local Government Area. Risk map: The population of the primary school-aged children was obtained from the demographic data of 2006 populations' census results. $\mathrm{N} \times 23 \% / 100=$ population of primary 
school age. The calculated primary school- aged children over the rate of infections using Geostatistical analyst extension in ArcGIS 10 was used for the risk map which was done with the aid of Geostatistical analyst wizard. Kriging and Cokriging method was used to produce the Risk map (Figure 4). From this map, the number of school-aged children (5-14years) at risk of intestinal parasitic infections in Rivers State is 655,061 (0.65million).

\section{Discussion}

The overreaching goal of the GIS was to create rate of infection, risk and prediction map of the prevalence of intestinal parasitic infections in relation to some environmental parameter. This result shows that these maps have been produced as shown. The distribution and prevalence of intestinal parasitic infections are greatly influenced by environmental factors affecting the human hosts. This is the same with many other parasitic diseases. It was evident that children from Emuoha, Ahoada East and parts of Ahoada West and Etche LGAs were more infected using the WHO prevalence classification system WHO, [17]. Many children from these areas had infection above $50 \%$ which could be referred to as very heavy infection. Part of Gokana, Tai, Oyigbo, Etche, Obio Akpor, Port Harcourt, Okrika, Ikwerre, Abua/Odual, Ahoada West and the entire Ogba/Egbema/Ndoni LGAs were heavily infected while children from the rest of the LGAs were moderately infected except part of Asari Toru that showed light infection. These findings

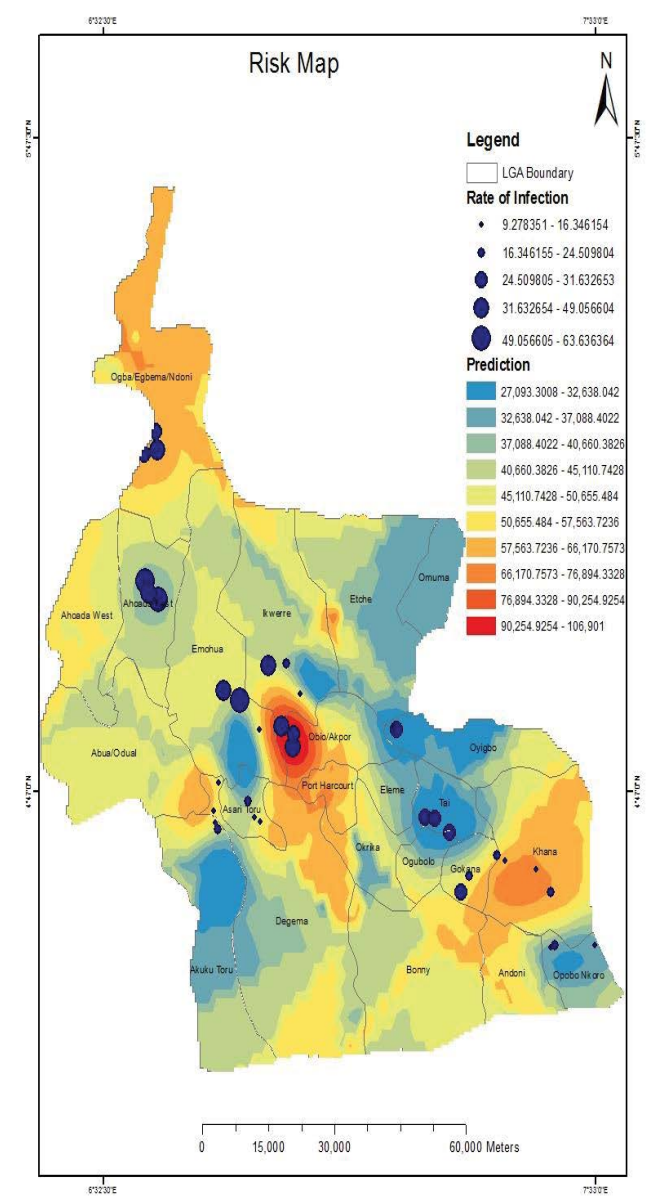

Figure 4: Risk map of prevalence of intestinal parasitic infections among primary school children in Rivers state Nigeria. would be of interest to Disease Control Programme Managers and Policy Makers in the State to define the extent of the problem and use intervention rationally. Despite the awareness of the effects of environmental factors on parasitic infections, not many attempts have been made to map the distribution of the intestinal parasitic infections in relation to specific environmental factors in Nigeria. Also there are no available data about the demography and hygienic conditions of the State's schools to help guide the development of school health programmes which are requirements for sustainable control of intestinal parasitic infections in school children. Presented in this study are the first rates of infection, risk and prediction maps of the distribution of intestinal parasitic infections in Rivers State. A similar map of urinary schistosomiasis in Ogun State exists Ekpo et al., [16] Other studies have used Altitude and Normalized Difference Vegetation Index (NDVI) to correlate the presence or prevalence of schistosomiasis as seen in Egypt, Ethopia, Tanzania and China where Altitude and NDVI were shown to be important environmental variables in the distribution of schistosomiasis. However, Ekpo et al., [16] reported that these factors did not correlate for urinary schistosomiasis. Altitude and NDVI affect both temperature and rainfall and restrict the distribution of snail species which are intermediate hosts or vectors of schistosomiasis. There is no variation in altitude and NDVI values in Rivers State; besides, the intestinal parasitic infections have direct life cycle and do not require an intermediate host or a vector. In areas where altitude and NDVI are used, there is a great variation of these variables due to topography, climate, and landmass [9]. Estimates of the number of school-aged children at risk of intestinal parasitic infections in Rivers State was lacking as they are the highest group at risk. Present study shows that the number of school-aged children (5-14years) at risk of intestinal parasitic infections in Rivers State is 655,061 (0.65million). This estimate represented the school-aged populations living in areas where the environmental factors, when combined with host/ parasite are suitable for the intestinal parasitic infections. However these are predictions does not necessary imply the number of schoolaged children infected. The rate of infection, risk and prediction map developed in this study provided detailed mapping of classified incidence and prevalence of intestinal parasitic infections in Rivers State. The fact that the model was derived from environmental variables and prevalence survey data had enabled the mapping of the disease and prediction of its burden across the State. These maps would be very relevant for planning treatment and interventions.

\section{References}

1. Ejezie GC and Igwe MA (1993) Human Ecology and Parasitic Infections in Nigeria. It's relationship between parasitic and anaemia. Jour Med Lab 3: 22 26.

2. Awogun IA, Okwerekwu FE, Ogawoye OA and Bello AB (1995) Helminthic infection and anaemia among pregnant women attending antenatal clinic in Ilorin, Nigeria. Nigeria Bioscience Res Comm 7: 41-45.

3. Adeyeba OA and Akinlabi MA (2002) Intestinal parasitic infection among school children in rural community, south west Nigeria. Nigerian Journal Parasitology 23: 11-18.

4. Ledor K and Weller P (2002) Giadiasis. In: Rise BD (ed), Infections Disease well slay mass.

5. Barnabas BB (2005) Prevalence of intestinal helminthiasis in school children from selected schools in Bida Nigeria, Nigeria journal of applied Acts and sciences 1: 22-26.

6. Sam-wobo SO Mafiana CF and Amusan SA (2005) Health knowledge and hygiene behaviors in relation to Ascariasis among school children, Ogun State, Nigeria tanzan. Health Res Bull 7: 62-66.

7. Ratard RC, Kouemeni LE, Ekani Bessala MM, Ndamkou CN, Sama MT, et al. 
Citation: Abah AE, Arene FOI, Okiwelu SN (2015) Assessment, Mapping and Prediction of the Spatial Distribution of Intestinal Parasitic Infections in Rivers State, Nigeria. J Trop Dis 3: 177. doi:10.4177/2329891X.1000177

Page 4 of 4

(1991) Ascariasis and trichuriasis in Cameroon. Trans R Soc Trop Med Hyg 85: 84-88.

8. Ratard RC, Kouemeni LE, Ekani Bessala MK, Ndamkou CN (1992) Distribution of hookworm infection in Cameroon. Ann Trop Med Parasitol 86: 413-418.

9. Brooker S, Kabatereine NB, Tukahebwa EM, Kazibwe F (2004) Spatial analysis of the distribution of intestinal nematode infections in Uganda. Epidemiol Infect 132: 1065-1071.

10. Saathoff E (2002) Geohelminth and Schistosoma Haematobium Infection in School children from Rural Northern KwaZulu-Natal/South Africa: Aspects of Control and Environmental and Behavioural Epidemiology: PhD Thesis, University of Copenhagen.

11. Campos MR, Valencia LI, Fortes Bde P, Braga RC, Medronho Rde A (2002) [Spatial distribution of Ascaris lumbricoides infection]. Rev Saude Publica 36: 69-74.

12. Noma M, Nwoke BE, Nutall I, Tambala PA, Enyong P, et al. (2002) Rapid epidemiological mapping of onchocerciasis (REMO): its application by the
African Programme for Onchocerciasis Control (APOC). Ann Trop Med Parasitol 96 Suppl 1: S29-39.

13. WHO (1991) Basic Laboratory Methods in Medical Parasitology. WHO Geneva 9-25.

14. Cheesbrough M (1999) District Laboratory Manual for tropical countries. (2ndedn), Bulterworth-heinemann Ltd. Oxford.

15. Raso G (2004) Assessment, mapping and prediction of spatial distribution of parasitic infections in Western Cote d'ivoire and implications for integrated control. Swiss Tropical Institute (STI), Basel, Switzerland.

16. Ekpo UF, Mafiana CF, Adeofun CO, Solarin ART and Idowu AB (2008) Geographical information systems (GIS) and risk maps of urinary schistosomiasis in Ogun State, Nigeria. Nigerian Journal of Parasitology 29 42-49.

17. WHO Expert Committee (2002) Prevention and control of schistosomiasis and soil-transmitted helminthiasis. World Health Organ Tech Rep Ser 912: 1-57. 